\title{
Inversion of the Slip Distribution of the 2017 Ms7.0 Jiuzhaigou Earthquake From InSAR
}

\section{Xiongwei Tang}

1. State Key Laboratory of Geodesy and Earth's Dynamic, Innovation Academy for Precision Measurement Science and Technology, Chinese Academy of Science, Wuhan 430077, China. 2.College of Earth and Planetary Sciences, University of Chinese Academy of Sciences, Beijing 100049, China.

\section{Rumeng Guo}

1. Earth System Science Programme, The Chinese University of Hong Kong, Shatin, Hong Kong, China.

2. State Key Laboratory of Geodesy and Earth's Dynamic, Innovation Academy for Precision Measurement Science and Technology, Chinese Academy of Science, Wuhan 430077, China.

Jianqiao Xu ( $\nabla$ xujq@asch.whigg.ac.cn )

State Key Laboratory of Geodesy and Earth's Dynamic, Innovation Academy for Precision Measurement Science and Technology, Chinese Academy of Science, Wuhan 430077, China https://orcid.org/00000003-3586-0652

\section{Heping Sun}

1. State Key Laboratory of Geodesy and Earth's Dynamic, Innovation Academy for Precision Measurement Science and Technology, Chinese Academy of Science, Wuhan 430077, China. 2.College of Earth and Planetary Sciences, University of Chinese Academy of Sciences, Beijing 100049, China.

\section{Xiaodong Chen}

State Key Laboratory of Geodesy and Earth's Dynamic, Innovation Academy for Precision Measurement Science and Technology, Chinese Academy of Science, Wuhan 430077, China.

\section{Jiangcun Zhou}

State Key Laboratory of Geodesy and Earth's Dynamic, Innovation Academy for Precision Measurement Science and Technology, Chinese Academy of Science, Wuhan 430077, China.

\section{Full paper}

Keywords: Jiuzhaigou earthquake, Fault geometry parameters, Coseismic slip distribution, InSAR

Posted Date: December 11th, 2020

DOl: https://doi.org/10.21203/rs.3.rs-125202/v1

License: (c) (1) This work is licensed under a Creative Commons Attribution 4.0 International License. Read Full License 



\section{Tile page}

Title: Inversion of the Slip Distribution of the 2017 Ms7.0 Jiuzhaigou Earthquake from InSAR

Author \#1: Xiongwei Tang, 1. State Key Laboratory of Geodesy and Earth's Dynamic, Innovation Academy for Precision Measurement Science and Technology, Chinese Academy of Science, Wuhan 430077, China. 2.College of Earth and Planetary Sciences, University of Chinese Academy of Sciences, Beijing 100049, China. tangxiongwei18@mails.ucas.edu.cn

Author \#2: Rumeng Guo, 1. Earth System Science Programme, The Chinese University of Hong Kong, Shatin, Hong Kong, China. 2. State Key Laboratory of Geodesy and Earth's Dynamic, Innovation Academy for Precision Measurement Science and Technology, Chinese Academy of Science, Wuhan 430077, China. rumengguo@cuhk.edu.uk

Author \#3: Jianqiao Xu, State Key Laboratory of Geodesy and Earth's Dynamic, Innovation Academy for Precision Measurement Science and Technology, Chinese Academy of Science, Wuhan 430077, China.xujq@asch.whigg.ac.cn

Author \#4: Heping Sun, 1. State Key Laboratory of Geodesy and Earth's Dynamic, Innovation Academy for Precision Measurement Science and Technology, Chinese Academy of Science, Wuhan 430077, China. 2.College of Earth and Planetary Sciences, University of Chinese Academy of Sciences, Beijing 100049, China. heping@asch.whigg.ac.cn

Author \#5: Xiaodong Chen, State Key Laboratory of Geodesy and Earth's Dynamic, Innovation Academy for Precision Measurement Science and Technology, Chinese Academy of Science, Wuhan 430077, China. chenxd@whigg.ac.cn

Author \#6: Jiangcun Zhou, State Key Laboratory of Geodesy and Earth's Dynamic, Innovation Academy for Precision Measurement Science and Technology, Chinese Academy of Science, Wuhan 430077, China. zjc@asch.whigg.ac.cn

Correspondence: xujq@asch.whigg.ac.cn

\section{Abstract}

On 8 August 2017, an Ms 7.0 earthquake occurred on a buried fault extending to the north of the Huya fault. Based on the coseismic deformation field obtained from Interferometric Synthetic Aperture Radar (InSAR) data and a series of finite fault model tests, we proposed a brand new two-fault model composed of a main fault and a secondary fault as the optimal model for the Jiuzhaigou earthquake, in which the secondary fault is at a large obtuse angle to the northern end of the main fault plane. Results show that the slip distribution is dominated by sinistral slip, with a significant shallow slip deficit. The main fault consists of two asperities, which is bounded by an aftershock gap may representing a barrier. In addition, we find that most of the aftershocks were located down-dip of the high-slip areas and laid in stress shadows. We deduce that the aftershocks may be controlled by the background tectonic stress field, 
and may be related to the velocity-strengthening zones.

Keywords Jiuzhaigou earthquake, Fault geometry parameters, Coseismic slip distribution, InSAR

\section{Main Text}

\section{Introduction}

On 8 August 2017, an Ms 7.0 earthquake occurred in Jiuzhaigou County, Aba Prefecture, Sichuan Province, China, with an epicenter at $103.82^{\circ} \mathrm{E}, 33.20^{\circ} \mathrm{N}$, and a focal depth of about $20 \mathrm{~km}$ (Institute of Geophysics, China Earthquake Administration, CEA-IGP). As of 13 August, the earthquake had caused 25 deaths, damaged more than 70,000 structures, and caused severe damage to the Jiuzhaigou scenic area (Li et al.2018). The Jiuzhaigou earthquake occurred near the northeastern boundary of the Bayan Har Block, indicating that the Bayan Har Block is still active (Zheng et al. 2020). Because the southeast movement of the Bayan Har Block is blocked by the North China Block and the South China Block, there are many broom-like branches on the eastern end of East Kunlun fault, which intersect with the Minjiang fault and the Huya fault, resulting in a complex seismic-tectonic environment in this region ( $\mathrm{Ji}$ et al. 2017). The NWWtrending Tazang fault, the northern segment of the NWW-trending Huya fault, and other nearby branches accommodate most of the sinistral strike-slip activity of the East Kunlun fault. The nearly NS-trending Minjiang fault and the southern segment of the Huya fault that are transverse compressional structures absorb the sinistral strike-slip motion of the remaining part of the East Kunlun fault, which causes the Minshan uplift on the eastern margin of the Tibetan Plateau (Xu et al.2017; Deng et al. 2014).

The complicated and intense tectonic activities of these faults result in the eastern margin of the Bayan Har Block being one of the most active regions in China, with many strong earthquakes occurring throughout history, such as the 1654 Tianshui earthquake $(M=8)$, the 1879 Wudu earthquake $(M=7)$, the 1933 Diexi earthquake $(M=7.5)$, the 1976 Songpan earthquakes $(M=7.2,6.7$, and 7.2), the 2008 Wenchuan earthquake $(M=8)$, and the 2013 Lushan earthquake $(M=7)$ (Fig. 1). The shorter duration, the continuous earthquakes, and the smaller strain of release compared to previous phases of earthquake clustering show that the Bayan Har Block is experiencing a peak in seismic activity (Deng et al. 2014). Therefore, further study of its seismogenic environment is urgently needed. The 2017 Jiuzhaigou earthquake provides a great opportunity to understand the tectonic loading mechanisms in this region.

Different research institutions have issued a series of reports on the focal mechanisms of the Jiuzhaigou earthquake. All of them have shown that the earthquake was a strike-slip event with a high-dip angle and a similar moment magnitude of 6.5, but there are obvious differences in the fault geometry (Table 1). No significant coseismic surface ruptures were observed for the Jiuzhaigou earthquake, which made it challenging to determine the seismogenic fault (Xu et al.2017; Ji et al. 2017). Although a large number of studies on the slip model of the Jiuzhaigou earthquake have 
been performed, a unified knowledge has not been obtained. Different one-fault models had a wide range of dip angles $\left(50^{\circ}-84^{\circ}\right)$ and a small range of strike angles $\left(152^{\circ}-\right.$ 155 $5^{\circ}$ (Nie et al. 2018; Chen et al. 2018; Zhao et al. 2018; Hong et al.,2018; Shan et al. 2017; Shen et al. 2019; Li et al.2018; Xie et al. 2018; Yi et al. 2017; Xu et al.2017). The two-fault models using the aftershock gap as the boundary had a small difference in fault geometry on the southern fault (strike: $145^{\circ}-148^{\circ}$, dip: $84^{\circ}-88^{\circ}$ ), but a larger difference on the northern fault (strike: $151^{\circ}-171^{\circ}$, dip: $77^{\circ}-88^{\circ}$ ) (Liu et al. 2019; Zheng et al. 2020; Hu et al. 2019). Sun et al. (2018) proposed a more complex threefault model to resolve the crustal deformation. Thus, it is necessary to further discuss the seismogenic fault and coseismic rupture model of the Jiuzhaigou earthquake. An accurate coseismic slip distribution can provide an accurate driving source for postseismic viscoelastic relaxation analysis, Coulomb stress change assessment, and ground motion simulations, which is of great practical significance for improving our understanding of the background tectonics of the source region and scientifically guiding earthquake relief efforts.

In this study, four finite fault models were assessed by the grid search method, and a two-fault model composed of a main fault and a secondary fault was finally determined as the optimal model for the seismogenic fault related to the Jiuzhaigou earthquake. In addition, we discussed the possible reason for the aftershock distribution and the occurrence of the seismic gap.

\section{Data and methods}

We used the coseismic deformation field in the line-of-sight direction based on Sentinel-1 SAR (synthetic aperture radar) images (2017/07/30, 2017/08/11) and using the Interferometric Synthetic Aperture Radar (InSAR) technique described by Ji et al. (2017) (Fig. 3a).

According to the Okada elastic dislocation theory, there is a linear relationship between the coseismic surface displacements and the fault dislocation distributions. Ideally, we can directly use the least-squares method to reverse the fault dislocation distributions. However, in practical problems, to describe the fault more objectively, we need to discrete it to many meshes. Moreover, the distribution of the surface observations is usually heterogeneous, and the Green function matrix is often rankdeficient or pathological. Generally, additional constraints are needed to ensure the stability of the inversion, and a dislocation smoothing constraint is usually used:

$$
F(s)=\|G s-d\|^{2}+\alpha^{2}\|L s\|^{2} \rightarrow \min ,
$$

Where $\boldsymbol{G}, \boldsymbol{s}$, and $\boldsymbol{d}$ are the Green function matrix, the vector composed of the dislocation of each of the sub-faults and the observed displacement vector on the surface, respectively. $\|\boldsymbol{G} \boldsymbol{s}-\boldsymbol{d}\|^{2}$ is the variance between the fit and the observation of the data. The second term is the smoothing constraint, where $\|L s\|^{2}$ is the dislocation distribution roughness and $\alpha$ is the smoothing factor. The value of the smoothing factor controls the trade-off between the model roughness and the misfit shown in Figure 2a. Generally, the "inflection point" is taken as a compromise. We used the steepest descent 
method (SDM) (Wang et al. 2013; Wang et al. 2003; Guo et al. 2018, 2019) to estimate the slip model of the Jiuzhaigou earthquake. Compared with other inversion methods, the SDM has an advantage in providing stable inversion results with a high efficiency, which is convenient to search for the optimal model quickly. The Green function used for the inversion was based on the Crust1.0 layered model (Laske et al. 2012).

\section{Model tests and results}

We first constructed a one-fault model (Additional file 1: Fig. S1a) to retrieve the surface deformation. To obtain a high-resolution finite fault slip model, we divided the entire fault into several $2 \mathrm{~km} \times 2 \mathrm{~km}$ rectangular sub-faults. The search results are shown in Fig. S2. Based on the trade-off curve, we choose an optimal smoothing factor of 0.1 . The optimal strike and dip angles are $154^{\circ}$ and $51^{\circ}$, respectively, which is similar to the model of Shan et al. (2017) $\left(\right.$ strike $=153^{\circ}$, dip $=50^{\circ}$ ). The one-fault model reproduces the observed surface deformation, and its residuals are mainly located on the southeastern end of the fault (Table 2, Additional file 1: Fig. S3). The slip is mainly dominated by sinistral strike-slip, while there is a partially thrust component on the southern segment of the fault and a small normal component on the northern segment of the fault (Additional file 1: Fig. S4). However, the model results in a significant slip on the southern end of the fault, which is not consistent with the fact that there were no surface ruptures.

In addition, given that the depth distribution of aftershocks is different from north to south and there is a seismic gap (Fang et al. 2018), we also constructed a two-fault model similar to the previous studies (Additional file 1: Fig. S1b, Zheng et al. 2020; Ji et al. 2017; Wang et al. 2019; Hu et al.2019; Liu et al. 2019; Xie et al. 2018). The tradeoff curve is shown in Fig. S5a, and we set the smoothing factor as 0.15 . Results indicate that the optimal model is composed of a northern fault $\left(\right.$ strike $=154^{\circ}, \operatorname{dip}=66^{\circ}$ ) and a southern fault $\left(\right.$ strike $=147^{\circ}$, dip $\left.=74^{\circ}\right)$ (Additional file 1: Fig. S5). Our preferred strikes are similar to the model of Zheng et al. (2020). The dip angle of our model in the north is smaller than that in the south, which is consistent with dip angles determined from the aftershocks (Hu et al.2019; Ji et al. 2017; Wang et al. 2019; Fang et al. 2018). Figure S6 shows that the two-fault model significantly improves the fit of the data (Table 2). The slip distribution is similar to that of Zheng et al. (2020), which is dominated by sinistral strike-slip. The average slip on the northern fault is larger than that on the southern fault, with a peak slip of $\sim 0.9 \mathrm{~m}$. The differences are that our results have a partial normal slip component on the northern fault, a smaller slip on the aftershock gap, and no significant slip near the surface (Additional file 1: Fig. S7). This is consistent with the characteristic of the Jiuzhaigou earthquake, which did not cause obvious surface ruptures.

Based on the coseismic deformation field and the aftershock distribution, Sun et al. (2018) proposed a secondary fault branch at the northern end of the main fault plane, which is at an obtuse angle relative to the main fault plane. The geological survey illustrates that there is indeed a secondary fault in this area (Yi et al. 2018). Therefore, we constructed a similar secondary fault (Additional file 1: Fig. S1c). Based on the trade-off curve, we choose 0.15 as the optimal factor. The optimal three-fault model is composed of a northern fault $\left(\right.$ strike $\left.=156^{\circ}, \operatorname{dip}=77^{\circ}\right)$, a southern fault $\left(\right.$ strike $=145^{\circ}$, 
$\left.\operatorname{dip}=82^{\circ}\right)$ and a secondary fault (strike $=204^{\circ}, \operatorname{dip}=80^{\circ}$ ) (Additional file 1: Fig. S8). The three-fault model further improves the fit of the data (Table 2, Additional file 1: Fig. S9). Figure S10 shows the slip distribution, which is similar to Sun et al. (2018). The slip of our model is more concentrated. The high-slip zone is located at a depth of $2-$ $10 \mathrm{~km}$ on the main fault, with a peak slip of $1.30 \mathrm{~m}$. The slip of the northern fault is composed of sinistral strike-slip and normal motion, while the southern fault is dominated by almost pure sinistral strike-slip motion. We conclude that the average slip of the northern fault is larger than that of the southern fault, and the secondary fault extends to the northeast of the main fault, which is consistent with the distribution of large number of aftershocks in this region.

As the fault geometry of the southern fault is similar to that of the northern fault in the optimal three-fault model, we proposed a new two-fault model composed of a main fault and a secondary fault, which was at an obtuse angle to the northern end of the main fault (Additional file 1: Fig. S1d). The trade-off curve shows that the smoothing factor is consistent with the three-fault model. Figure 2 shows that the optimal strikes of the main fault (Seg1) and the secondary fault (Seg2) are $151^{\circ}$ and $196^{\circ}$, respectively, and their dips are both $77^{\circ}$. The two-fault model has the best fit among these four models (Table 2). The southeastern region of the main fault, which is poorly recovered by the other models, is satisfactorily resolved by this new model (Fig. 3). According to the surface deformation, the fit of the data, the aftershock distribution, the slip dislocation, and the background tectonics, we proposed that this two-fault model was the optimal model for the Jiuzhaigou earthquake. Results show that the slip of the main fault is primarily sinistral strike-slip with a small amount of normal component, which is distributed within $2 \mathrm{~km}-8 \mathrm{~km}$ with a peak slip of $1.51 \mathrm{~m}$ (Fig. 4c). The asperity on the northern segment is composed by a partial small amount of normal slip, which is consistent with the focal mechanism solution determined by the USGS (Table 1). In addition, the slip of the secondary fault extends up to $11 \mathrm{~km}$, with a peak slip of $0.85 \mathrm{~m}$ (Fig. 4b). The obtained moment magnitude is 6.5 , which is consistent with the seismic moment obtained by several different institutions (Table 1). There is no significant slip near the ground surface, which is consistent with the absence of obvious surface ruptures caused by the Jiuzhaigou earthquake. These all further verify the robustness and reliability of our model.

\section{Discussion}

In our optimal model, the secondary fault is at a large obtuse angle to the main fault. This large obtuse angle branching is also called backward branching. Similar phenomena were also observed in the 1992 Landers earthquake (Fliss et al.2005) and the 1999 Hector Mine earthquake (Oglesby et al. 2003). The mechanism of this backward branching is the rupture stopping or slowing down on the main fault plane, which causes the rupture to jump to a nearby fault (Fliss et al. 2005). This phenomenon is also accommodated by a significant shallow slip deficit (Oglesby et al. 2003). Apparently, no significant surface ruptures were observed in the Jiuzhaigou earthquake. There was a small slip zone at the southern end of the junction between the backward branching and the main fault, which may have been caused by a rigid block stopping or slowing down the rupture on the main fault. All of these facts are consistent with the 
conditions for the occurrence of obtuse faults. Moreover, the 1992 Landers earthquake and the 1999 Hector Mine earthquake both occurred within a complicated fault system. The Jiuzhaigou earthquake was also related to a similar fault system, which indicates that the Jiuzhaigou earthquake had a weak fault plane, small strain accumulations, and a complex rupture process (Sun et al. 2018).

Based on the relocated aftershocks, there was an aftershock gap of $\sim 5 \mathrm{~km}$ in the northwest of the mainshock, which may have been caused by one of the following three factors. (1) The coseismic slip was large and the stress release was sufficient. (2) The strikes of the faults changed at this turning-point. (3) There were unbroken asperities (Fang et al. 2018). The three-fault model indicated that the geometry parameters of the northern fault are similar to those of the southern fault. The small amount of surface deformation in the aftershock gap in the line-of-sight direction indicates that there was no significant coseismic slip below, which is also verified by the slip model. Therefore, we rule out the first two possibilities and suggest that unbroken asperities may have prevented the rupturing of these sections of the fault.

Figure 4 illustrates that most of the aftershocks occurred in the coseismic high-slip down-dip area, presenting a complementary pattern. Generally, it can be interpreted with (1) direct triggering from coseismic stress change (Stein et al. 1995) or (2) aftershocks that driven by afterslip in the velocity-strengthening zone (Guo et al. 2019, 2020). Therefore, we first used the numerical code PSGRN/PSCMP (Wang et al. 2006) following the strategies of Guo et al. (2020) to estimate the static Coulomb stress changes caused by the coseismic slip. Since the Jiuzhaigou earthquake was a strikeslip event, we set the effective friction coefficient to 0.4 ( Lin et al. 2019; Shan et al. 2017; Guo et al. 2020; Wang and Xu 2017). We used the slip model as the driving source. The receiver fault was set to our preferred fault model. Results show that most of aftershocks occurred in the Coulomb stress shadows (Additional file 1: Fig. S11). Therefore, we propose that the aftershock distribution may be related to aseismic afterslip, indicating the velocity-strengthening region. In addition, Helmstetter and Shaw (2006) suggested that the aftershocks on the fault plane and in adjacent areas may have been related to the tectonic stress on the fault, which may explain the inconsistency between the mechanisms of the aftershocks and that of the mainshock. Therefore, we calculated the static Coulomb stress changes on the optimally oriented failure planes for the 2017 Jiuzhaigou earthquake under the tectonic background stress field. In this study, we set the maximum principal stress, middle principal stress and minimum principal stress to $-10^{4} \mathrm{kPa},-10^{3} \mathrm{kPa}$, and $0 \mathrm{kPa}$ according to Toda et al. (2005), respectively (Wang and $\mathrm{Xu}$ 2017). However, there is a relatively large uncertainty here. Figure 5 reveals the static Coulomb stress changes at different depths and the distribution of the aftershocks within $\pm 2.5 \mathrm{~km}$, from which we found that most of the aftershocks occurred in the region where the Coulomb stress increased. Therefore, the aftershocks of the Jiuzhaigou earthquake may be controlled by the background tectonic stress field.

\section{Conclusion}

In this study, we tested four different finite fault models based on the InSAR data and determined a brand new two-fault model for the $M w 6.5$ Jiuzhaigou earthquake. 
The high-slip regions in the main fault are concentrate at $2-8 \mathrm{~km}$, with a peak slip of $1.51 \mathrm{~m}$. There are two asperities, which are perfectly demarcated by the aftershock gap may indicating a barrier. The secondary fault is at a large obtuse angle to the main fault, whose slip extends to $11 \mathrm{~km}$, with a peak slip at $0.85 \mathrm{~m}$. The main fault of the Jiuzhaigou earthquake is the NW-trending hidden fault of the Huya fault, which is one of the branches of the East Kunlun fault. There are few aftershocks at both ends of the main fault where the Coulomb stress increases, so we should pay attention to the occurrence of subsequent aftershocks in this region.

\section{Declarations}

Ethics approval and consent to participate

Not applicable

\section{Consent for publication}

Not applicable

\section{List of abbreviations}

NEDC: Data Sharing Infrastructure of National Earthquake Data Center

GCMT: Global Centroid Moment Tensor, Harvard University Global Moment Tensor Solution

USGS: United States Geological Survey

CEA-IGP: Institute of Geophysics, China Earthquake Administration

CEA-IEF: Institute of Earthquake Forecasting, China Earthquake Administration,

SDM: steepest descent method

\section{Availability of data and materials}

The InSAR data used in this study were provided by Lingyun Ji (http://dx.doi.org/10.6038/cjg20171032)

\section{Competing interests}

The authors declare that there are no competing interests.

\section{Funding}

This research was supported by the B-type Strategic Priority Program of the Chinese Academy of Sciences (Grant Number XDB41000000), the National Natural Science Foundation of China (Grant Numbers 41974023, 41874094, 41674083, 41874026).

\section{Authors' contributions}

XT constructed and assessed the four optimal finite fault models, calculated the coseismic Coulomb stress changes and drafted the manuscript writing. RG contributed to the design. RG, JX, HS, XC, and JZ helped to review and edit the manuscript.

\section{Acknowledgments}

We thank the National Earth System Science Data Center, National Science \& Technology Infrastructure of China (http://www.geodata.cn) for the data provided. We are grateful to Lingyun Ji of the Second Monitoring Center, China Earthquake Administration for providing the InSAR data. We used the Generic Mapping Tools (GMT) open-source collection of computer software tools to create the figures, which is developed and maintained by Paul Wessel and Walter H. F. Smith.

\section{References:}


Chen W, Qiao XJ, Liu G, Xiong W, Jia ZG, Li Y, Wang YB, You ZL, Long F (2018) Study on the coseismic slip model and Coulomb stress of the 2017 Jiuzhaigou MS7.0 earthquake constrained by GNSS and InSAR measurements. Chinese Journal Of Geophysics 61(5): 2122-2132. https://doi.org/10.6038/cig2018L0613. (in Chinese with English abstract)

Deng Q, Cheng SP, Ma J, Du P (2014) Seismic activities and earthquake potential in the Tibetan Plateau. Chinese Journal Of Geophysics 57(7): 2025-2042._https://doi.org/10.6038/cjg20140701. (in Chinese with English abstract)

Fang LH, Wu JP, Su JR, Wang MM, Jiang C, Fan LP, Wang WL, Wang CZ, Tan XL (2018) Relocation of mainshock and aftershock sequence of the Ms7.0 Sichuan Jiuzhaigou earthquake. Chinese Science Bulletin 63(7): 649-662.https://doi.org/10.1360/N972017-01184. (in Chinese with English abstract)

Fliss S, Bhat HS, Dmowska R, Rice JR (2005) Fault branching and rupture directivity. Journal of Geophysical Research Solid Earth 110(B6) https://doi.org/10.1029/2004jb003368.

Guo RM, Zheng Y, An C, Xu JQ, Jiang ZS, Zhang LP, Riaz MS, Xie J, Dai K, Wen YM (2020) The 2018 Mw 7.9 Offshore Kodiak, Alaska, Earthquake: An Unusual Outer Rise Strike - Slip Earthquake. Journal of Geophysical Research: Solid Earth 125 https://doi.org/10.1029/2019JB019267.

Guo RM, Zheng Y, Diao FQ, Xu J (2018) Rupture model of the 2013 M W 6.6 Lushan (China) earthquake constrained by a new GPS data set and its effects on potential seismic hazard. Earthq Sci 31: 117-125. https://doi.org/10.29382/eqs-2018-0117-1.

Guo RM, Zheng Y, Xu JQ (2020) Stress modulation of the seismic gap between the 2008 M s 8.0 Wenchuan earthquake and the $2013 \mathrm{M} \mathrm{s} 7.0$ Lushan earthquake and implications for seismic hazard. Geophysical Journal International 221: 2113-2125. https://doi.org/10.1093/gji/ggaa143.

Guo RM, Zheng Y, Xu JQ, Jiang ZS (2019) Seismic and Aseismic Fault Slip Associated with the 2017 M w 8.2 Chiapas, Mexico, Earthquake Sequence. Seismological Research Letters 90: 1111-1120. https://doi.org/10.1785/0220180262.

Helmstetter A, Shaw BE (2006) Relation between stress heterogeneity and aftershock rate in the rateand-state model.

Hong SY, Zhou X, Zhang K, Meng GJ, Dong YF, Su XN, Zhang L, Li S, Ding KL (2018) Source Model and Stress Disturbance of the 2017 Jiuzhaigou Mw 6.5 Earthquake Constrained by InSAR and GPS Measurements. Remote Sensing 10(9) http://dx.doi.org/10.3390/rs10091400.

Hu XH, Sheng SZ, Wang YG, Liang SS (2019) Fault Plane Parameters of 2017 Jiuzhaigou Ms7. 0 Earthquake Determined by Aftershock Distribution. Journal Of Seismological Research 42(3): 366371. (in Chinese with English abstract)

Ji LY, Liu CJ, Xu J, Liu L, Long F, Zhang ZW (2017) InSAR observation and inversion of the seismogenic fault for the 2017 Jiuzhaigou MS7.0 earthquake in China. Chinese J. Geophys 60(10): 4069-4082. http://dx.doi.org/10.6038/cjg20171032. (in Chinese with English abstract)

Laske G, Masters G, Ma Z, Pasyanos ME (2012) CRUST1.0: An updated global model of Earth's crust. EGU General Assembly (14).

Li Q, Tan K, Wang DZ, Nie ZS, Zhao B, Zhang R, Li Y (2018) Joint inversion of GNSS and teleseismic data for the rupture process of the 2017 Mw6.5 Jiuzhaigou, China, earthquake. J Seismol 22: 805814. https://doi.org/10.1007/s10950-018-9733-1.

Lin X, Chu RS, Zeng XF (2019) Rupture processes and Coulomb stress changes of the $2017 \mathrm{Mw} 6.5$ Jiuzhaigou and $2013 \mathrm{Mw} 6.6$ Lushan earthquakes. Earth, Planets and Space 71(1): - 
https://doi.org/10.1186/s40623-019-1061-3.

Liu G, Xiong W, Wang Q, Qiao XJ, Ding KH, Li XX, Yang SM (2019) Source Characteristics of the 2017 Ms 7.0 Jiuzhaigou, China, Earthquake and Implications for Recent Seismicity in Eastern Tibet. Journal of Geophysical Research Solid Earth https://doi.org/10.1029/2018JB016340.

Nie ZS, Wang DJ, Jia ZG, Yu PF, Li LF (2018) Fault model of the 2017 Jiuzhaigou Mw 6.5 earthquake estimated from coseismic deformation observed using Global Positioning System and Interferometric Synthetic Aperture Radar data. 70: 55. https://doi.org/10.1186/s40623-018-0826-4. Oglesby DD, Day SM, Li Y, Vidale JE (2003) The 1999 Hector Mine Earthquake: The Dynamics of a Branched Fault System. Bulletin of the Seismological Society of America 93(6): 2459-2476. https://doi.org/10.1785/0120030026.

Qu CY, Zhang GH, Shan XJ, Zhang GF, Song XG, Liu YH (2013) Coseismic deformation derived from analyses of $\mathrm{C}$ and $\mathrm{L}$ band SAR data and fault slip inversion of the Yushu Ms7.1 earthquake, China in 2010. Tectonophysics 584: 119-128. https://doi.org/10.1016/j.tecto.2012.05.011.

Shan B, Zheng Y, Liu CL, Xie ZJ, Kong J (2017) Coseismic Coulomb failure stress changes caused by the 2017 M7.0 Jiuzhaigou earthquake, and its relationship with the 2008 Wenchuan earthquake. SCIENCE CHINA Earth Sciences 60(12): 2181-2189. https://doi.org/10.1007/s11430-017-9125-2.

Shan XJ, Qu CY, Gong WY, Zhao DZ, Zhang GF (2017) Coseismic deformation field of the Jiuzhaigou MS7.0 earthquake from Sentinel-1A InSAR data and fault slip inversion. Chinese J. Geophys 60(12): 4527-4536. http://doi.org/10.6038/cjg20171201. (in Chinese with English abstract)

Shen WH, Li YS, Jiao QS, Xie QC, Zhang JF (2019) Joint inversion of strong motion and InSAR/GPS data for fault slip distribution of the Jiuzhaigou 7.0 earthquake and its application in seismology. Chinese J. Geophys. (in Chinese) 61(1): 115-129. http://dx.doi.org/10.6038/cjg2019L0541. (in Chinese with English abstract)

Stein RS, King GCP, Lin J (1995) Stress triggering of the 1994 M = 6.7 Northridge, California, earthquak by its predecessors. International Journal of Rock Mechanics and Mining Sciences \& Geomechanics Abstracts 265(5177): 1432-1435. https://doi.org/10.1016/0148-9062(95)90030-9.

Sun JB, Yue H, Shen ZK, Zhan Y, Sun XY (2018) The 2017 Jiuzhaigou Earthquake: A Complicated Event Occurred in a Young Fault System. Geophysical Research Letters 45(5): 2230-2240. https://doi.org/10.1002/2017GL076421.

Toda S, Stein RS, Richards-Dinger K, Bozkurt SB (2005) Forecasting the evolution of seismicity in southern California: Animations built on earthquake stress transfer. Journal of Geophysical Research B: Solid Earth 110(5): 1-17. https://doi.org/10.1029/2004JB003415.

Wang JJ, Xu CJ (2017) Coseismic Coulomb stress changes associated with the 2017 MW6.5 Jiuzhaigou earthquake (China) and its impacts on surrounding major faults. Chinese Journal Of Geophysics 60(11): 4398-4420. https://doi.org/10.6038/cjg20171127. (in Chinese with English abstract)

Wang R, Diao F, Hoechner A (2013) SDM - A geodetic inversion code incorporating with layered crust structure and curved fault geometry.

Wang R, Lorenzo-Martín F, Roth F (2006) PSGRN/PSCMP-a new code for calculating co- and postseismic deformation, geoid and gravity changes based on the viscoelastic-gravitational dislocation theory. Computers \& Geosciences 32(4): 527-541. https://doi.org/10.1016/j.cageo.2005.08.006.

Wang R, Martı n FL, Roth F (2003) Computation of deformation induced by earthquakes in a multilayered elastic crust-FORTRAN programs EDGRN/EDCMP. Computers \& Geosciences 29(2): 195-207. https://doi.org/10.1016/S0098-3004(02)00111-5. 
Wang Y, Zhao T, Li CX, Liu C (2019) Relocations and focal mechanism solutions of the 2017 Jiuzhaigou, Sichuan MS 7.0 earthquake sequence. Process in Geophysics 34(2): 469-478. https://doi.org/10.6038/pg2019CC0050.

Xie ZJ, Zheng Y, Yao HJ, Fang LH, Zhang Y, Liu CL, Wang MM, Shan B, Zhang HP, Ren JJ, Ji LY, Song MQ (2018) Preliminary analysis on the source properties and seismogenic structure of the 2017 Ms7.0 Jiuzhaigou earthquake. Sci. China Earth Sci 61: 339-352. https://doi.org/10.1007/s11430-017-9161-y.

Xu XW, Chen GH, Wang QX, Chen LC, Ren ZK, Xu C, Wei ZY, Lu RQ, Tan XB, Dong SP, Shi F (2017) Discussion on seismogenic structure of Jiuzhaigou earthquake and its implication for current strain state in the southeastern Qinghai-Tibet Plateau. Chinese J. Geophys 60(10): 4018-4026. http://dx.doi.org/10.6038/cjg20171028. (in Chinese with English abstract)

Yi GX, Long F, Liang MJ, Zhang HP, Zhao M, Ye YQ, Zhang ZW, Qi YP, W WS, Gong Y, Qiao HZ, Wang Z, Qiu GL, Su JR (2017) Focal mechanism solutions and seismogenic structure of the 8 August 2017 M7.0 Jiuzhaigou earthquake and its aftershocks, northern Sichuan. Chinese Journal Of Geophysics 60(10): 4083-4097.https://doi.org/10.6038/cig20171033. (in Chinese with English abstract)

Yi SJ, Wu CH, Li YS, Huang C (2018) Source tectonic dynamics features of Jiuzhaigou Ms 7.0 earthquake in Sichuan Province, China. J. Mt. Sci 15 https://doi.org/10.1007/s11629-017-4703-6.

Zhao DZ, Qu CY, Shan XJ, Gong WY, Zhang YF, Zhang GH (2018) InSAR and GPS derived coseismic deformation and fault model of the 2017 Ms7.0 Jiuzhaigou earthquake in the Northeast Bayanhar block. Tectonophysics 726: 86-99. https://doi.org/10.1016/j.tecto.2018.01.026.

Zheng A, Yu X, Xu W, Chen X, Zhang W (2020) A hybrid source mechanism of the 2017 Mw 6.5 Jiuzhaigou earthquake revealed by the joint inversion of strong-motion, teleseismic and InSAR data. Tectonophysics 789: 228538. https://doi.org/10.1016/j.tecto.2020.228538.

Zhong L (2007) InSAR Imaging of Volcanic Deformation over Cloud-prone Areas - Aleutian Islands. Photogrammetric Engineering \& Remote Sensing 73(3): 245-257. https://doi.org/10.14358/PERS.73.3.245.

\section{Figure Legends}

Figure 1 Tectonic setting. (a) Tectonic setting of the eastern margin of the Tibetan Plateau. The solid blue and purple lines indicate the primary and secondary block boundaries, respectively. The green circles represent historical earthquakes $(M \geq 5)$ (from the NEDC). The black beach balls show the focal mechanism solutions of the historical earthquakes ( $M \geq 6.5$ ) near the Jiuzhaigou earthquake (from the GCMT). The red beach ball represents the focal mechanism solution of the Jiuzhaigou earthquake. The red rectangle is the region shown in (b). (b) Tectonic setting of the Jiuzhaigou earthquake. The blue circles are the spatial distributions of the aftershocks from Fang et al. (2018), and the red rectangle is the projection of our optimal fault model on the surface. The red, black, gray and purple beach balls and marks show the focal mechanism solutions determined by the GCMT, USGS, CEA-IGP, and CEA-IEF, respectively. A, B, and C, are the Tibetan Block, the South China Block, and the North China Block, respectively. A1, A2, and A3 are the Qiangtang Block, the Bayan Har 
block and the Qilian Block, respectively. The data are from the NEDC (Data Sharing Infrastructure of National Earthquake Data Center, http://data.earthquake.cn), the GCMT (Global Centroid Moment Tensor, Harvard University Global Moment Tensor Solution, https://www.globalcmt.org/), the USGS (United States Geological Survey, https://www.usgs.gov/), the CEA-IGP (Institute of Geophysics, China Earthquake Administration, http://www.cea-igp.ac.cn/en/), and the CEA-IEF (Institute of Earthquake Forecasting, China Earthquake Administration, http://www.ief.ac.cn/)

Figure 2 Search results of the brand new two-fault model. (a) Trade-off curve between the roughness and the fit of the data. (b) Dip angle of the main fault (Seg1). (c) Dip angle of the secondary fault (Seg2). (d) Strike angle of the main fault (Seg1). (e) Strike angle of the secondary fault (Seg2)

Figure 3 Simulation results of distributed slip model (the brand new two-fault model). (a) Coseismic deformation field from InSAR data. (b) Simulated deformation field. (c) Residuals

Figure 4 Distribution of the coseismic slip and aftershocks of the Jiuzhaigou earthquake. (a) The distribution of the aftershocks and the projection of the rectangular faults on the surface. (b) Slip distribution of the secondary fault. (c) Slip distribution of the main fault and the projection of the aftershocks onto the main fault plane. The white cycles represent the aftershocks

Figure 5 Static Coulomb stress changes on the 3D optimally oriented failure planes created by the Jiuzhaigou earthquake at different depths and the distribution of the aftershocks within $5 \mathrm{~km}$. (a) Coulomb stress changes at a depth of $5 \mathrm{~km}$. (b) Coulomb stress changes a depth of $10 \mathrm{~km}$. (c) Coulomb stress changes a depth of $15 \mathrm{~km}$

\section{Table Legends}

Table 1 Focal mechanism solutions of the 2017 Jiuzhaigou earthquake determined by different institutions

Table 2 Parameters of four finite fault models

\section{Additional files:}

Additional files 1: Figure S1 Projections of the four finite fault models onto the surface: (a)The one-fault model. (b)The two-fault model (a northern fault and a southern fault). (c)The three-fault model. (d)The brand new two-fault model (a main fault and a secondary fault)

Figure S2 Search results of the optimal one-fault model. (a) Trade-off curve between the roughness and the fit of the data. (b) Dip angle. (c) Strike angle

Figure S3 Simulation results of distributed-slip model (the one-segment fault model).

(a) Coseismic deformation field from InSAR data. (b) Simulated deformation field.

(c)Residuals

Figure S4 Distribution of the slip (one-fault model)

Figure S5 Search results of the optimal two-fault model. (a) Trade-off curve between the roughness and the fitness of data. (b) Dip angle of the northern fault (Seg1). (c) Dip angle of the southern fault (Seg2). (d) Strike angle of the northern fault (Seg1). (e) 
Strike angle of the southern fault (Seg2)

Figure S6 Simulation results of distributed-slip model (the two-segment fault model). (a) Coseismic deformation field from InSAR data. (b) Simulated deformation field. (c) Residuals

Figure S7 Distribution of the slip (two-fault model). (a) Slip distribution of the northern fault. (b) Slip distribution of the southern fault

Figure S8 Search results of the optimal three-fault model. (a) Trade-off curve between the roughness and the fitness of data. (b) Dip angle of the northern fault (Seg1). (c) Dip angle of the secondary fault (Seg2). (d) Dip angle of the southern fault (Seg3). (e) Strike angle of the northern fault (Seg1). (f) Strike angle of the secondary fault (Seg2). (g) Strike angle of the southern fault (Seg3)

Figure S9 Simulation results of distributed-slip model (the three-fault model). (a) Coseismic deformation field from InSAR data. (b) Simulated deformation field. (c)Residuals

Figure S10 Distribution of the slip (three-fault model). (a) Slip distribution of the northern fault. (b) Slip distribution of the secondary fault. (c) Slip distribution of the southern fault

Figure S11 Static Coulomb stress changes caused by the Jiuzhaigou earthquake at different depths and the distribution of the aftershocks within $5 \mathrm{~km}$. (a) Coulomb stress changes at a depth of $5 \mathrm{~km}$. (b) Coulomb stress changes at a depth of $10 \mathrm{~km}$. (c) Coulomb stress changes at a depth of $15 \mathrm{~km}$ 


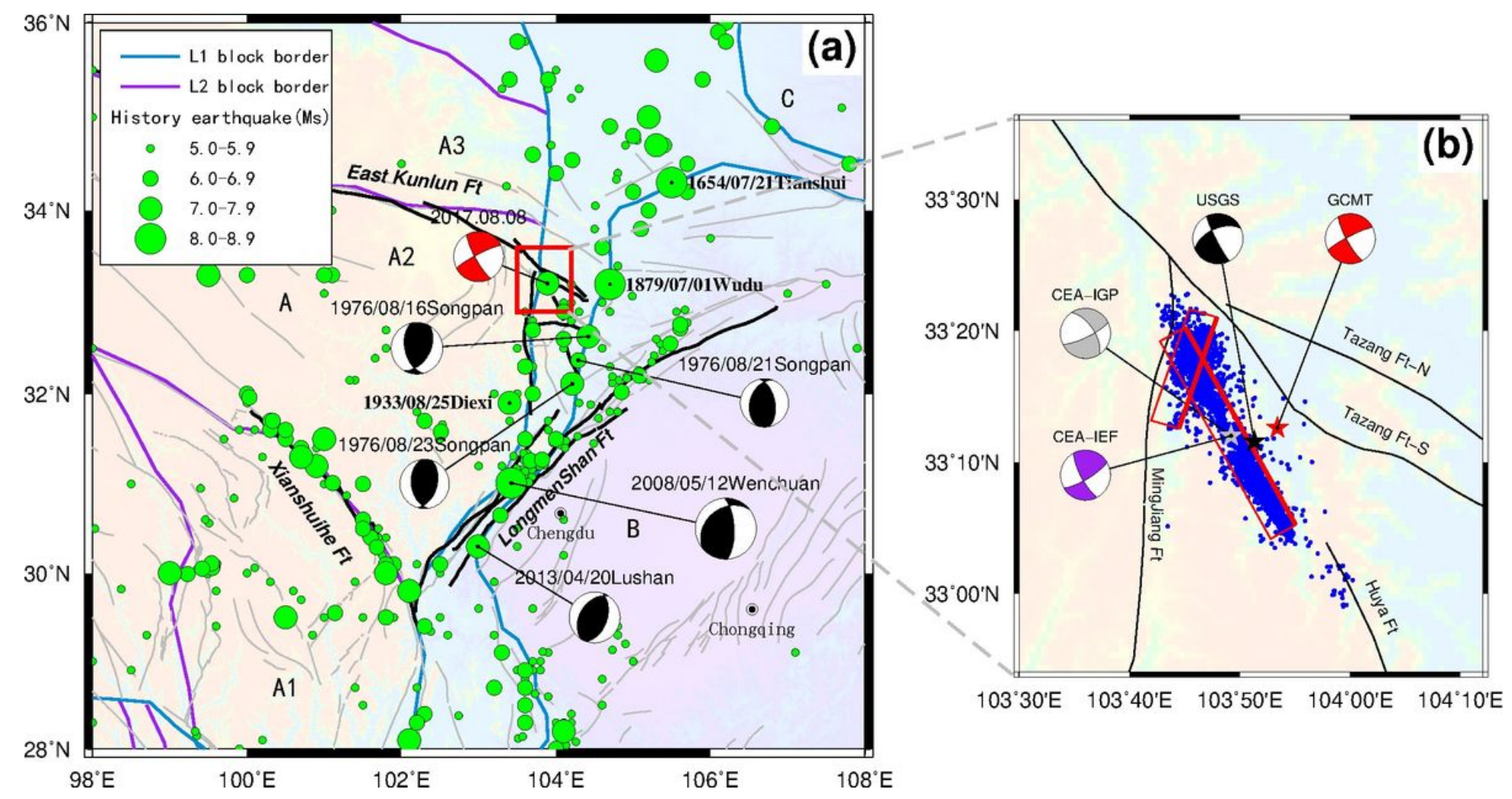

\section{Figure 1}

Tectonic setting. (a) Tectonic setting of the eastern margin of the Tibetan Plateau. The solid blue and purple lines indicate the primary and secondary block boundaries, respectively. The green circles represent historical earthquakes ( ) (from the NEDC). The black beach balls show the focal mechanism solutions of the historical earthquakes ( ) near the Jiuzhaigou earthquake (from the GCMT). The red beach ball represents the focal mechanism solution of the Jiuzhaigou earthquake. The red rectangle is the region shown in (b). (b) Tectonic setting of the Jiuzhaigou earthquake. The blue circles are the spatial distributions of the aftershocks from Fang et al. (2018), and the red rectangle is the projection of our optimal fault model on the surface. The red, black, gray and purple beach balls and marks show the focal mechanism solutions determined by the GCMT, USGS, CEA-IGP, and CEA-IEF, respectively. A, B, and C, are the Tibetan Block, the South China Block, and the North China Block, respectively. A1, A2, and A3 are the Qiangtang Block, the Bayan Har block and the Qilian Block, respectively. The data are from the NEDC (Data Sharing Infrastructure of National Earthquake Data Center, http://data.earthquake.cn), the GCMT (Global Centroid Moment Tensor, Harvard University Global Moment Tensor Solution, https://www.globalcmt.org/), the USGS (United States Geological Survey, https://www.usgs.gov/), the CEA-IGP (Institute of Geophysics, China Earthquake Administration, http://www.cea-igp.ac.cn/en/), and the CEA-IEF (Institute of Earthquake Forecasting, China Earthquake Administration, http://www.ief.ac.cn/ ) Note: The designations employed and the presentation of the material on this map do not imply the expression of any opinion whatsoever on the part of Research Square concerning the legal status of any 
country, territory, city or area or of its authorities, or concerning the delimitation of its frontiers or boundaries. This map has been provided by the authors.
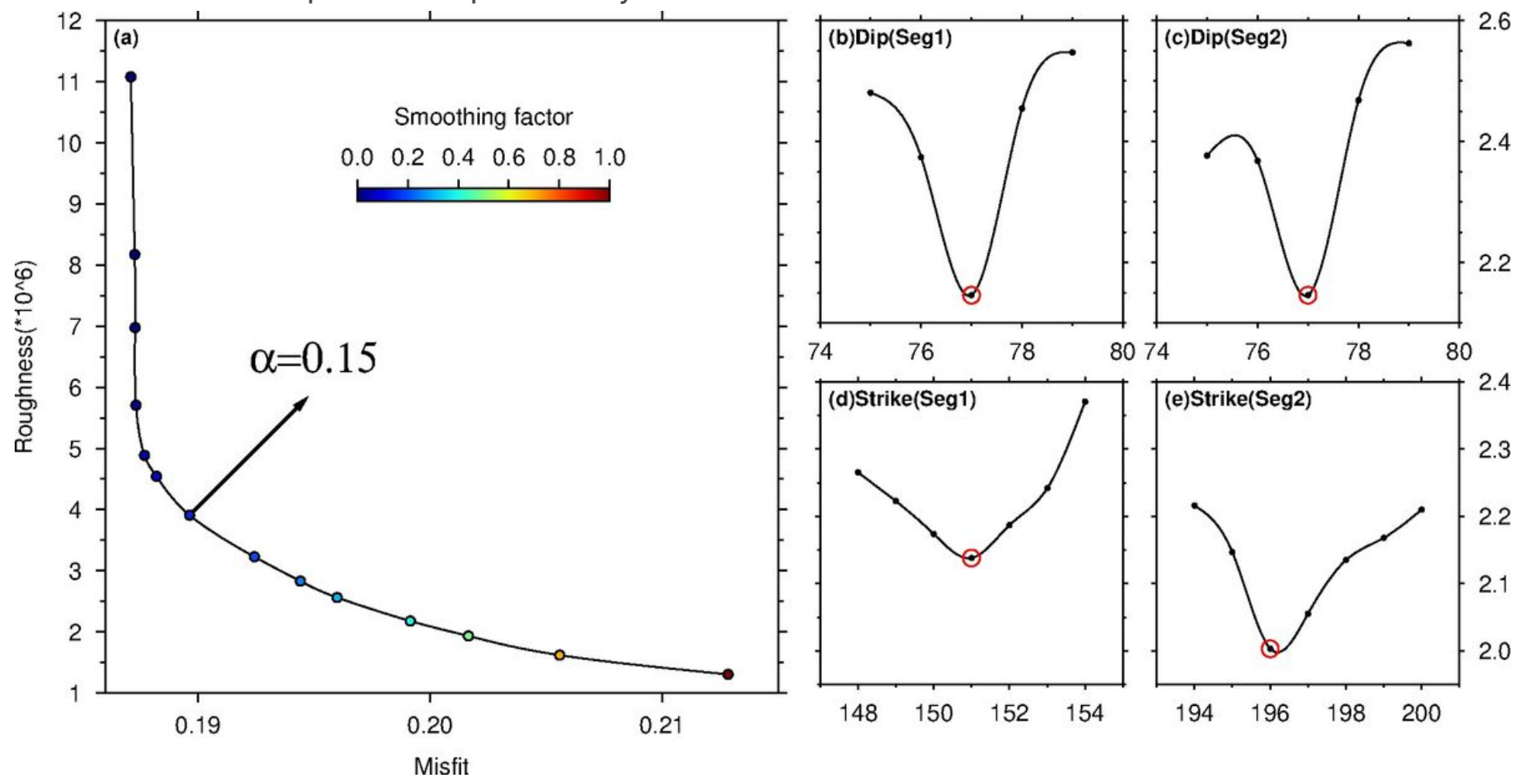

Figure 2

Search results of the brand new two-fault model. (a) Trade-off curve between the roughness and the fit of the data. (b) Dip angle of the main fault (Seg1). (c) Dip angle of the secondary fault (Seg2). (d) Strike angle of the main fault (Seg1). (e) Strike angle of the secondary fault (Seg2)
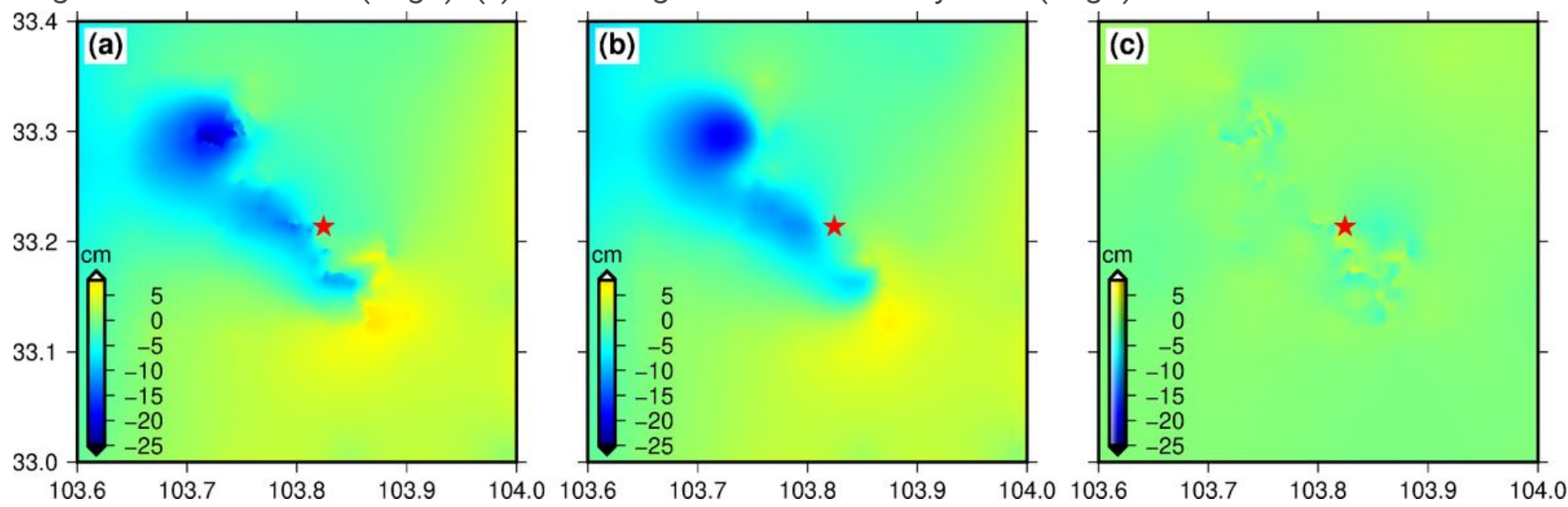

Figure 3

Simulation results of distributed slip model (the brand new two-fault model). (a) Coseismic deformation field from InSAR data. (b) Simulated deformation field. (c) Residuals 


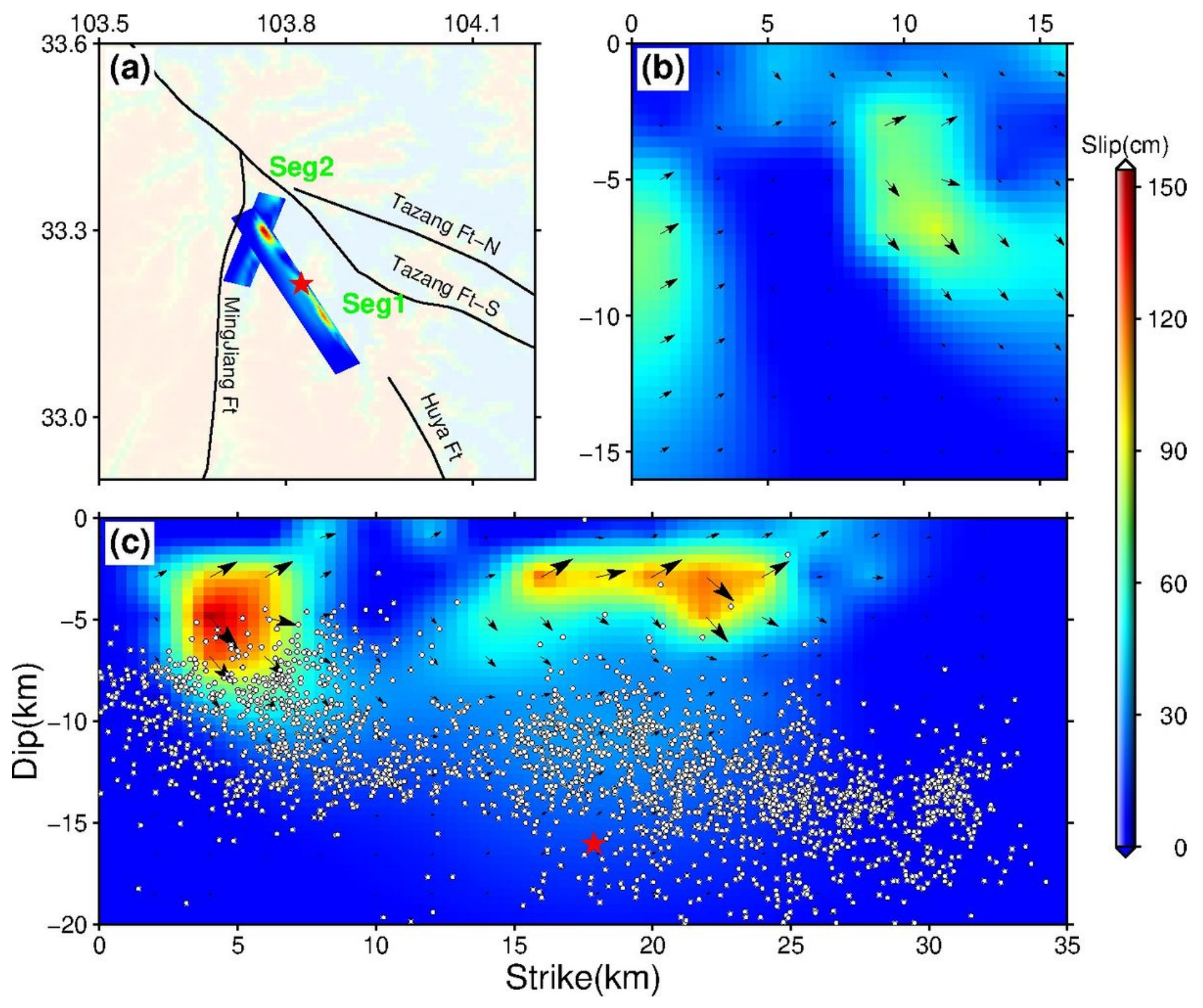

Figure 4

Distribution of the coseismic slip and aftershocks of the Jiuzhaigou earthquake. (a) The distribution of the aftershocks and the projection of the rectangular faults on the surface. (b) Slip distribution of the secondary fault. (c) Slip distribution of the main fault and the projection of the aftershocks onto the main fault plane. The white cycles represent the aftershocks Note: The designations employed and the presentation of the material on this map do not imply the expression of any opinion whatsoever on the part of Research Square concerning the legal status of any country, territory, city or area or of its authorities, or concerning the delimitation of its frontiers or boundaries. This map has been provided by the authors. 

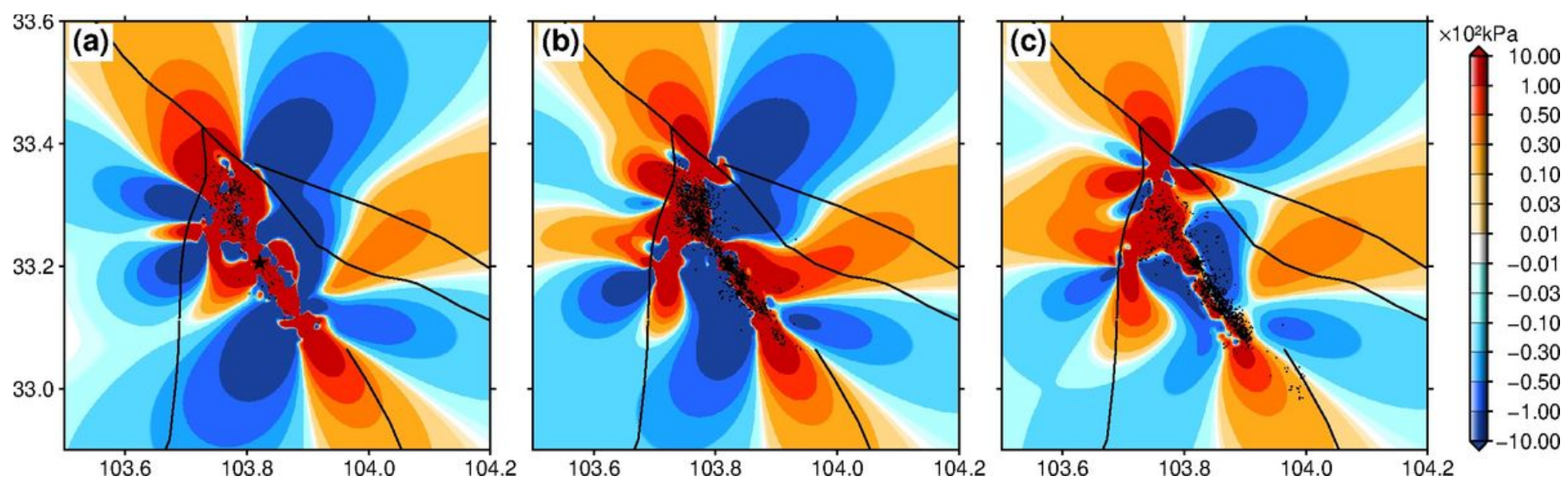

Figure 5

Static Coulomb stress changes on the 3D optimally oriented failure planes created by the Jiuzhaigou earthquake at different depths and the distribution of the aftershocks within $5 \mathrm{~km}$. (a) Coulomb stress changes at a depth of $5 \mathrm{~km}$. (b) Coulomb stress changes a depth of $10 \mathrm{~km}$. (c) Coulomb stress changes a depth of $15 \mathrm{~km}$

\section{Supplementary Files}

This is a list of supplementary files associated with this preprint. Click to download.

- FigureS1.jpg

- FigureS10.jpg

- Table2.xlsx

- Table1.xlsx

- FigureS11.jpg

- FigureS2.jpg

- FigureS3.jpg

- FigureS4.jpg

- FigureS5.jpg

- FigureS6.jpg

- FigureS7.jpg

- FigureS8.jpg

- FigureS9.jpg

- Graphicalabstract.jpg 